\title{
Silver nano fabrication using leaf disc of Passiflora foetida Linn
}

\author{
Bipin D. Lade ${ }^{1} \cdot$ Anita S. Patil ${ }^{1}$
}

Received: 23 February 2017/ Accepted: 22 March 2017/Published online: 1 April 2017

(C) The Author(s) 2017. This article is an open access publication

\begin{abstract}
The main purpose of the experiment is to develop a greener low cost SNP fabrication steps using factories of secondary metabolites from Passiflora leaf extract. Here, the leaf extraction process is omitted, and instead a leaf disc was used for stable SNP fabricated by optimizing parameters such as a circular leaf disc of $2 \mathrm{~cm}$ $(1,2,3,4,5)$ instead of leaf extract and grade of $\mathrm{pH}(7,8$, $9,11)$. The SNP synthesis reaction is tried under room temperature, sun, UV and dark condition. The leaf disc preparation steps are also discussed in details. The SNP obtained using (1 mM: $100 \mathrm{ml} \mathrm{AgNO}_{3}+$ singular leaf disc: $\mathrm{pH} 9,11)$ is applied against featured room temperature and sun condition. The UV spectroscopic analysis confirms that sun rays synthesized SNP yields stable nano particles. The FTIR analysis confirms a large number of functional groups such as alkanes, alkyne, amines, aliphatic amine, carboxylic acid; nitro-compound, alcohol, saturated aldehyde and phenols involved in reduction of silver salt to zero valent ions. The leaf disc mediated synthesis of silver nanoparticles, minimizes leaf extract preparation step and eligible for stable SNP synthesis. The methods sun and room temperature based nano particles synthesized within 10 min would be use certainly for antimicrobial activity.
\end{abstract}

Bipin D. Lade

dbipinlade@gmail.com

Anita S. Patil

anitapatil@sgbau.ac.in

1 Department of Biotechnology, Lab No 106, Microbial Biotechnology and Secondary Metabolite Lab, Sant Gadge Baba Amravati University, Amravati, Maharashtra 444602, India
Keywords Silver nano particle - Leaf disc $\cdot$ Passiflora foetida UV spectroscopic analysis · FTIR · Antimicrobial

\section{Introduction}

The nanoparticles formulation is beneficial for several fields that include electronic, textile, mobile phones, geo sensing technology, robotics, paper, space, food, construction, fertilizers, pesticides and agrochemical industries. However, potential nanoparticle needs manipulating of chemicals, salts and other necessary items. The optimization and editing leads to specific size and shape NP potential for human benefits (Sadowski 2010). The plants used for production of nano particles may be pronounced as Phyto-nano factories (Kesharwani et al. 2009; Prabhu and Poulose 2012; Bhosale et al. 2014). The noble silver $(\mathrm{Ag})$ is the metal of choice for synthesis of nano particles across the field of the biological system, living organisms and medicine. It is used for storing drinking water in ancient times. Thus, the idea of combining $\mathrm{Ag}$ with reducing agent to form nano sized Ag-structure with better efficiency; efficacy and activity are possible. The silver nanoparticles are the vintage and preferred target of the green method related to against bacteria property of zero valent silver and easy reduction of silver salt to form zero valent silver (Singh et al. 2014; Kharissova et al. 2009) These Ag-NP $(<100 \mathrm{~nm})$ are used for wound healing, burns and other medical purposes. The silver nano particles possessed antibacterial property which makes it suitable for development into novel curative, pharmaceutical, textile, paint, food and agriculture industries.

It is identified that $15 \%$ of product on a global market is having some kind of nanotechnology incorporated during processing, and it is expected to reach US \$ 1 trillion 
(Husen and Siddiqi 2014). There are several sources used for synthesis of nano particles such as, noble metals, i.e. silver, titanium dioxide, zinc oxide, Platinum, Gold and Paledium. However, silver $(\mathrm{Ag})$ is used for formulation of bulk coins, which was replaced by ionic silver and in current, it is molded for colloidal silver NP (Kharissova et al. 2013; Rai et al. 2012). It is used in the nitrate form to induce the antimicrobial effects, but when silver nanoparticles are used, there is a huge increase in the surface area to interact with microbes efficiently. There are some common methods used for synthesis of nanoparticles such as physical and chemical.

The chemical and physical methods are the most common options for NP synthesis due to its advantage of synthesized NP are stable, colloidal dispersions in water or organic solvents. However, these chemical methods use noxious chemicals in the synthesis protocol which affects environment, plant, animals and humans. Thus, nanobiotechnologist are finding new strategies to overcome hazardous synthesis methods and to come up with methods, techniques, pharma product that is pollution-free and nonharmful to environment. The nanobiotechnologist have used the greener route for NP fabrication called as green way of nano particle synthesis. The Green biology area covers huge names such as natural substance, silver chemistry, green technology, polymers, green polymerization, green engineering, manufacturing, food preservative, textile, waste-water treatment, particle technology, bio fuel, biomass, bio-composites and wet chemistry (Kharissova et al. 2009). The greener source for SNP formulation is simple, eco-friendly, low cost, less time consuming with advantage of easy large-scale production using common reducing, capping, and stabilizing agents (Bonde 2011; Iravani 2011). Some of the examples of Green routes for nano formulation are natural products, amino acid, winery waste, table sugar, glucose and polyphenols. It also includes plant extract, leaf extracts, seed extracts, stem extracts; fruit extracts, root extract and flower extracts. Even the combination of extracts may be used. The leaf is mostly a choice of sample for reduction of $\mathrm{AgNO}_{3}$. Usually leaf of plant contains several functional groups such as alkanes, alkyne, amines, aliphatic amine, carboxylic acid; nitro-compound, alcohol, saturated aldehyde, glutathione and phenols, which involve for reduction of $\mathrm{AgNO}_{3}$ to $\mathrm{Ag}$ (Kumar et al. 2015; Balavandy et al. 2014). The strong broad peak located at $425-475 \mathrm{~nm}$ indicates the reduction of $\mathrm{Ag}^{+}$ions to zero valent atom confirmed the formation of silver nanoparticles similar to findings to other plant species as silver characteristic absorbance observed by (Banerjee et al. 2014).

The reduction of $\mathrm{AgNO}_{3}$ to $\mathrm{Ag}$ by glutathione (GSH), as reducing agent and stabilizer agent can be explained as an example. The glutathione (GSH) is biotic and abiotic stress compound produced in plants, which is made up of a reactive thiol group to reduce the metal salts. GHS is a tripeptide consisting of glutamic acid, cysteine and glycine units and is a ubiquitous antioxidant present in human and plant cells. The thiol $(-\mathrm{SH})$ and acetyl $(-\mathrm{COO})$ groups of GSH behave as capping agent and bonds with the positively charged surface of Ag-NPs. A detail of interaction between the charged Ag-NPs and GSH is shown in Figs. 1 and 2 , shows the possible chemical equation for glutathione (GSH) reduces silver ions to Ag-NPs. The dispersion of silver ions in the aqueous solution of GSH matrix (Equation 1), GSH reacted with the $\mathrm{Ag}^{+}$to form a GSH complex $[\mathrm{Ag}(\mathrm{GSH})]^{+}$, which reacted to form [Ag (GSH)] (Equation 2 ). The colorless solution turned to pale yellow in few minutes and changed to dark brown after $72 \mathrm{~h}$ (Balavandy et al. 2014). However, the general process of silver nano particle synthesis using plant extracts is given in Fig. 3. The complete process is divided into three phases as activation, nucleation and growth phase (Keat et al. 2015). The prevalent good example for synthesis of AgNps using<smiles>N[C@@H](CCC(=O)N[C@@H](CS)C(=O)NCC(=O)O)C(=O)O</smiles>

(Glutathione)

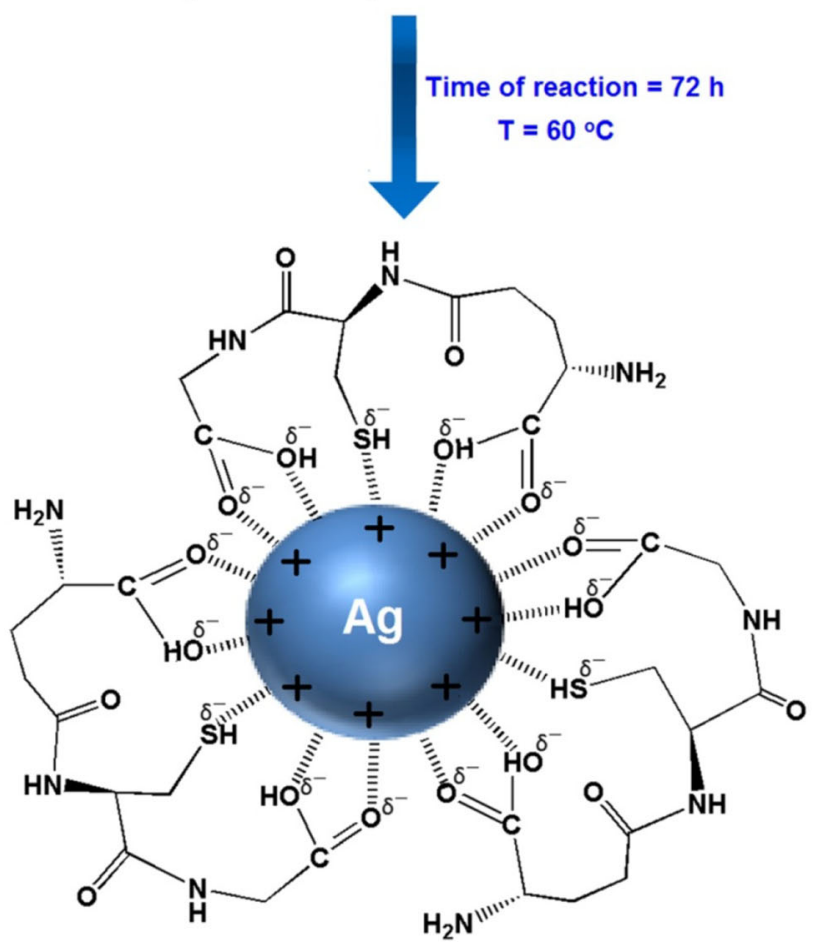

Fig. 1 Shows a detail of interaction between the charged Ag-NPs and glutathione (GSH) (Balavandy et al. 2014) 


$$
\mathrm{Ag}_{(\mathrm{aq})}^{+}+\mathrm{GSH}_{(\mathrm{aq})} \rightarrow[\mathrm{Ag}(\mathrm{GSH})]_{(\mathrm{aq})}^{+}
$$

$$
[\mathrm{Ag}(\mathrm{GSH})]_{(\mathrm{aq})}^{+} \frac{\mathrm{T}=60^{\circ} \mathrm{C}, \quad \mathrm{t}=72 \mathrm{~h} 0}{(+1 \mathrm{e})}[\mathrm{Ag}(\mathrm{GSH})] \downarrow
$$

Fig. 2 Shows the possible chemical equation for glutathione (GSH) reduces silver ions to Ag-NPs. This chemical reduction equation has been retrieved from (Balavandy et al. 2014)

biomolecules of $P$. tripartita is given by (Kumar et al. 2015).

The genus Passiflora is geographically distributed in tropical and sub tropical parts throughout the world. A 600 diversified species has been reported in Central America, Africa, South-East Asia, Pacific region and in the state of Parana, Brazil and South America (Garboza and Corona 1994). A passion flower has been reported as a symbol for Passion of Christ (Brindha et al. 2012) and its attractive flower compromise of 100 petals that resemble as Kauravas, 5 stamens resemblance Pandavas, 3 stigmas as Brahma, Visnu and Shiva characters from historical Mahabharata in India (Lade 2015). These species usually grow in spiky trees as support and over the surface of alongside a road and lava flow, volcanic and limestone soils and is grown in waste land (Lijavetzky et al. 2008). The minimum rainfall required for $P$. foetida is $900 \mathrm{~mm}$. The preferred temperature range is $19-29{ }^{\circ} \mathrm{C}$ for seedlings and $13-38{ }^{\circ} \mathrm{C}$ for adult plants (CABI 2017). The geographical variation distribution of this plant species has evolved plant to inherit several photochemical such as alkaloids, phenols, glycoside flavonoids and cyanogenic compounds, Five cyanohydrin glycosides with a cyclopentene ring, tetraphyllin $\mathrm{A}$, tetraphyllin $\mathrm{B}$, tetraphyllin B sulphate, deidacin and volkenin were reported in $P$. foetida (Patil et al. 2013). Three polyketides $\alpha$-pyrones, named passifloricins is unique to this species only (Mohanasundari et al. 2007; Echeverri et al. 2001). Traditionally, the plant has been used for its properties like antiproliferative, sedative, anti antibacterial, leishmanicidal, antispasmodic, emetic, dressing for wounds and antiulcer (Suganya et al. 2016). Even though Passiflora species have tremendous potential, still they remain unexplored from use in formation of silver nanoparticles.

The green synthesis of silver nanoparticles from Passiflora species such as Passiflora vitifolia (Ghosh et al. 2015), Passiflora tripartita (Kumar et al. 2015), Passiflora foetida (Brindha et al. 2012) was studied. The ethanolic extract of $P$. foetida based SNP is reported, However, no literature on aqueous extracts is available. The few reports were in direction for synthesis and characterization of iron oxide nanoparticles prepared by $P$. foetida aqueous extract and is confirmed by UV spectroscopic analysis. Its average-size particles were determined by XRD. SEM was used to determine its morphology and FTIR analysis done to evaluate function group involved in reduction of iron oxide (Suganya et al. 2016; Shekhawat et al. 2014). The work of (Shekhawat et al. 2014) report the biosynthesis of Zinc oxide nanoparticles from the aqueous extracts of leaves, stem, roots, and flowers, immature and mature fruits of $P$. foetida $\mathrm{L}$.

Several available methods are used for the biosynthesis of Ag-NP such as ultrasound, microwave, UV radiation, aerosol technologies, lithography, laser ablation, ultrasonic fields and photochemical reduction. All these methods require consumption of energy from heat, electricity and high-priced chemicals, which are expensive and use hazardous chemicals. Thus, an eco-friendly method that uses minimum energy, electricity, less time required for completion of reaction, non toxic is the area of interest in current research work. As plant based nano fabrication is efficient for large-scale synthesis of NP here in this section the main focus is given on silver nanoparticles synthesis based on plant leaf disc. The leaf disc has very simple preparation, cost effective, reproducible, results in stable, eco-friendly NP. It requires a leaf disc, $\mathrm{AgNO}_{3}$ and doubled distilled water and mixture are kept in a flask for reaction to happen. The leaf disc of $P$. foetida diffuses phyto chemical, secondary metabolites, which act as a reducing/capping agent for synthesis of silver nanoparticles.
Fig. 3 Shows the generalized mechanism of plant mediated synthesis of metal nanoparticles (Banerjee et al. 2014)

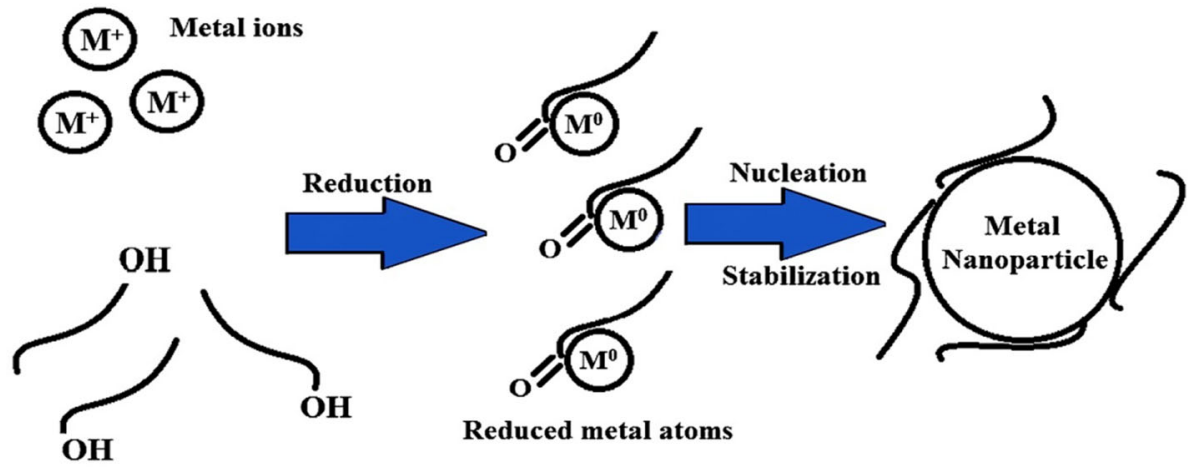

Plant reducing agent 
To come up with new method idea for SNP synthesis, the minimization of leaf extracts preparation step is the main priority, necessary parameters such as $\mathrm{pH}$ and reaction condition have been managed for silver nano fabrication. The present paper deals with discussion on green synthesis of silver nanoparticles by extract free method. An elaborate explanation of synthesized SNP characterization via analytical techniques, to analyze, identify the green silver nanoparticles is presented. A sincere effort is made to develop a quick, low-cost and greener method, which eliminates the leaf extract preparation step for synthesis of silver nanoparticles.

\section{Method structure}

The unique method for synthesis of silver nanoparticle is demonstrated here; we tried to avoid any electric source (magnetic stirring, heating, boiling) to be still very traditional. Here, there is an omission of leaf extract ( $P$. foetida) preparation step. The concept is that instead of leaf extraction, a leaf disc of $2 \mathrm{~cm}$ in diameter is directly placed in required volume of $\mathrm{AgNO}_{3}$ and observed for reduction of silver salt for silver nano particle synthesis. The present method for synthesis of silver nanoparticle requires leaf sample, beaker, doubled distilled water; $\mathrm{AgNO}_{3}$ and reaction performed in presence of sun light.

\section{Materials}

The material required for silver nanoparticles formulation uses $250 \mathrm{ml}$ flask, double distilled water, $100 \mathrm{ml}$ measuring cylinder, $\mathrm{AgNO}_{3}$, P. foetida leaf. The chemicals for SNP experimentation vary according to the need of research. The instruments such as UV spectrophotometry, Fourier transforms infrared spectroscopy (FTIR), LM 20, and zeta potential are used (Nano Composix 2012).

\section{Methods}

A leaf sample is cut in $2 \mathrm{~cm}$ in diameter using two test tube; test tube 1 is at base in upright position and test tube 2 placed in inverted position over the 1st test tube (open face of the test tube is facing towards each other), and a single leaf ( $P$. foetida) is placed in between both tubes. Both the tubes are rotated in appositive direction such a way that a leaf is cut into circular disc shape. This leaf disc containing a secondary metabolites, polyphenol, polysaccharides is used for reduction of silver salt. The reducing agents from leaf disc are diffused out and reduce the silver salt to stable zero valent atoms. The current method uses a very little amount of leaf sample for silver nano assembly.

\section{Sample collection}

The $P$. foetida leaf sample is recovered from its natural habitat from an Amravati University campus garden (Bonde 2011). The P. foetida contents diversified secondary metabolites such as Phenols, Polyphenol, Saponins, Tannins, Cardiac Glycosides, Alkaloid, Anthraquinones, Steroid, Flavonoid, passifloricins, polyketides, and alphapyrones and several other chemical compounds (Patil and Paikrao 2012). These chemical compounds are potential to reduce silver nitrate to zero valent silver thus such compounds are called as inherent to reduce silver salt/ions (Balavandy et al. 2014).

\section{Leaf disc preparation}

The leaf disc of $P$. foetida is prepared which contains metabolites, polyphenol and polysaccharides used for reduction of $\mathrm{AgNO}_{3}$. The plant leaf is taken in between two test tube that are kept in face to face (see Fig. 4) and rotated in appositive direction. This brings the circular shape cut leaf disc, and it may be collected at a lower test tube. This disc either singular or plural is used for nanoparticles synthesis. Figure 4 displays complete step wise protocol of leaf disc preparation from $P$. foetida leaves samples. The excised leaf disc of $P$. foetida used as reducing agent for silver nanoparticle; in experimentation, it is used as singular, double, triple, four disc, penta disc and so on. In this way large no of disc could be prepared and used as per experimentation.

\section{Silver nanoparticles synthesis}

As $\mathrm{AgNO}_{3}$ is highly expensive and in experimentation it is required in very minute quantity, thus for preparation of $1 \mathrm{mM} \mathrm{AgNO}{ }_{3}$ a stock of $100 \mathrm{mM}$ of aqueous solution of silver nitrate $\left(\mathrm{AgNO}_{3}\right)$ was prepared and used for optimization experiments of AgNP synthesis. The leaf disc of Passiflora species is prepared and dipped in $100 \mathrm{ml}(1 \mathrm{mM}$ $\mathrm{AgNO}_{3}$ ). The mixture is placed in room temperature and observed for color change as an indication of silver nanoparticles synthesis. This is the one-step process for green silver nanoparticles synthesis (Vijayaraghavan et al. 2012; Dhawan et al. 2004).

\section{Checked parameters}

The silver nano particles are synthesized at different $\mathrm{pH}$ ( $\mathrm{pH} 7, \mathrm{pH} 8, \mathrm{pH} 9$ ) with constant $100 \mathrm{ml}$ of $1 \mathrm{mM} \mathrm{AgNO}_{3}$, single leaf disc of $2 \mathrm{~cm}$ at room temperature and $\mathrm{pH} 11$ (sun condition). Figure 5 shows the complete process of green synthesis of AgNPs under SUN condition. The leaf disc $P$. foetida singular, double and plural are immersed in $\mathrm{AgNO}_{3}$ $100 \mathrm{ml}$ for reduction of silver salt. The desired $\mathrm{pH}$ of 
Fig. 4 Represent the complete step wise process of leaf disc preparation from $P$. foetida leaves samples. a The leafs of $P$. foetida from which the leaf disc has been removed in a grade of time scale by disc preparation method; the remaining leaf part attached to plant can be used for certain invivo secondary metabolites extraction (may called as wound stress). b The leaf disc size is of $\sim 2 \mathrm{~cm}$ shown using a steel scale. c The sandwich leaf between two test tube, one from top and second from below. $\mathbf{d}$ The two test tube were sandwich leaf is twisted in oppositive direction. e The oppositive direction rotation of test tubes cut the leaf in the same shape of the test tube surface. $\mathbf{f}, \mathbf{g}, \mathbf{h}$ The excised leaf disc of $P$. foetida used as reducing agent for silver nanoparticle
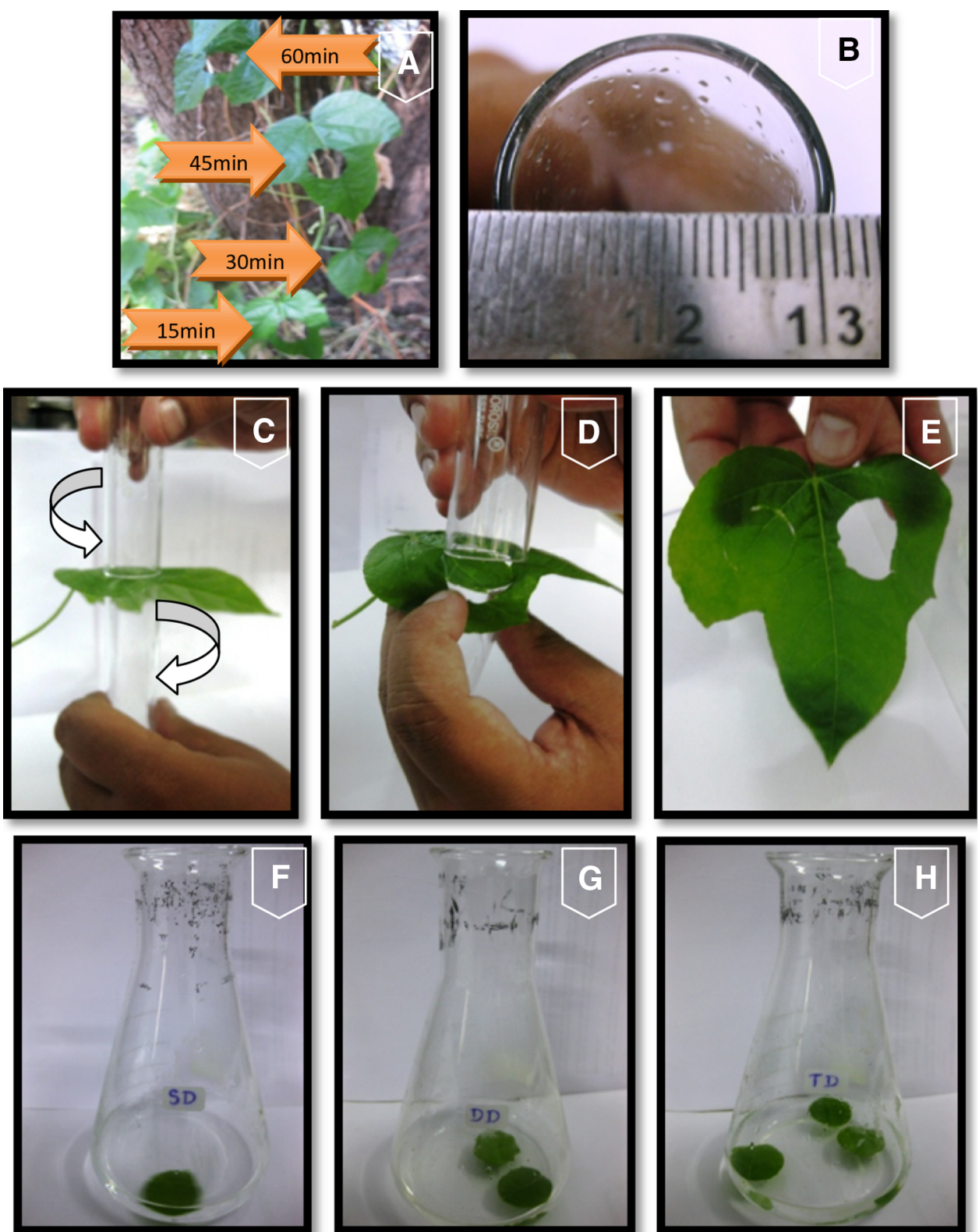

mixture is adjusted using $\mathrm{NaOH}$ solution. Further, the sample is used for three different conditions (sun, UV, dark) by keeping optimized $\mathrm{pH} 9$ constant. It was observed that reaction carried under sun condition shows sharp peak at $420 \mathrm{~nm}$ UV-Vis absorbance and found suitable and favors the silver nano particle synthesis when compared with dark and UV conditions. The sample at $\mathrm{pH} 11$ at sun condition is used for variable numbers of a leaf disc of $2 \mathrm{~cm}$ such as $1,2,3,4$, and 5 .

\section{UV-Vis analysis}

Ultraviolet-visible analysis was done using Shimadzu Dual Beam spectrometer (ModelUV-1650 PC) operated at a resolution of $1 \mathrm{~nm}$. Reduction of $\mathrm{Ag}^{+}$ion was monitored by measuring UV-Vis spectrum of mixture. Reduction of silver ions to zero valent silver was confirmed by color change from colorless green to dark black brown.

\section{FTIR analysis}

FT-IR measurement was carried out for silver nitrate, $P$. foetida from fresh leaf veins, from fresh leaf part other than veins to identify the possible bioactive molecules responsible for the reduction of the $\mathrm{Ag}^{+}$ions and the capping of the bio reduced silver nanoparticles. The leaf part is directly used for FTIR analysis, and the spectrum was recorded in the wavelength interval $4000-400 \mathrm{~cm}^{-}$. 


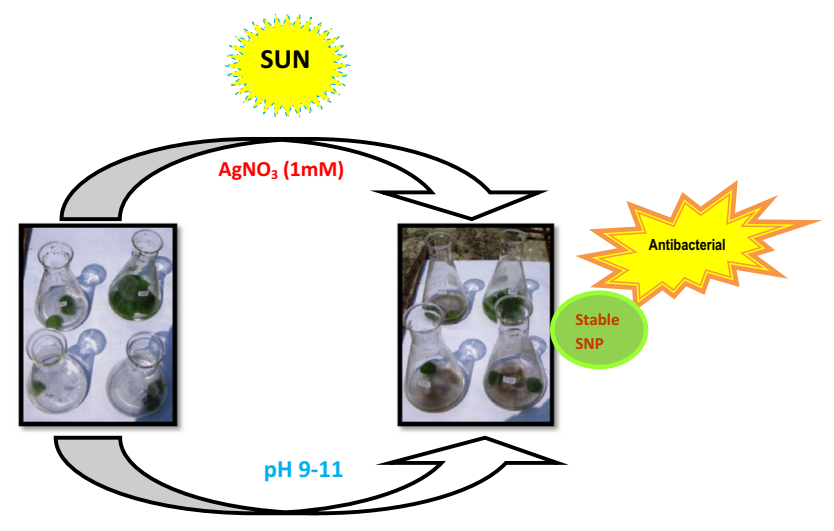

Fig. 5 It shows the complete process of green synthesis of AgNPs under SUN condition. From left to right the leaf disc P. foetida singular, double and plural are immersed in $\mathrm{AgNO}_{3} 100 \mathrm{ml}$ for reduction of silver salt. The desired $\mathrm{pH}$ of mixture is adjusted using $\mathrm{NaOH}$ solution. The color of solution changes forms colorless to light green-orange-brown and terminally to dark-brown black. The SNP raised would be beneficial for antimicrobial activity

\section{SEM analysis of silver nanoparticles}

Scanning electron Microscopic (SEM) analysis was done using Carl Zeiss SEM-EVO18. Thin films of the sample were prepared on a carbon coated copper grid by just dropping a very small amount of the sample on the grid. Extra solution was removed using a blotting paper and then the films on the SEM grid were allowed to dry by putting it under a mercury lamp for $5 \mathrm{~min}$.

\section{Result and discussion}

The green synthesis of silver nanoparticles (Arokiyaraj et al. 2014) using leaf disc of $P$. foetida was carried out in the present study. There are several reports that confirmed phytochemical such as Alkaloids, Phenolic compounds and Tannins in P. foetida (Kumar et al. 2015). The work of (Pushpa Rani and Amila Meera 2015) confirmed Alkaloids, Carbohydrates, Glycosides, Flavonoids, Proteins, Steroids and Tannins. Thus, P. foetida is considered as eligible for synthesis of silver nanoparticles. Polyphenols and flavonoids seemed to be responsible for the biosynthesis of these NPs (Iravani et al. 2014). In literature, few reports suggest the use of potential $P$. foetida for nanoparticles synthesis with no publication for silver nanoparticles using leaf disc of $P$. foetida. However, recently (Kumar et al. 2015) used aqueous leaf extracts of $P$. foetida for green synthesis of iron oxide nanoparticles. They found phenolic compounds to be very effective, reducing and stabilizing agents for NP based on phytochemical results. The silver nanoparticles synthesized using leaf disc of $P$. foetida were centrifuged at $4000 \mathrm{rpm}$ to form a pellet. This is used for further characterization of silver nanoparticles.

\section{Characterization of silver nanoparticles}

The silver nano particle synthesized is confirmed and characterized using UV spectroscopic analysis (Balavandy et al. 2014). However, initial conformation is the change in color observed from light green to dark brown-black color. The brown color of silver solutions provided a spectroscopic indication for formation of SNP. Similar observation for color changes over the reaction time was monitored by (Kumar et al. 2015). The extract color changes from light pink to light brown and finally to dark brown. The FTIR analysis revels the functional group participated in silver reduction. The zeta potential is used for identification of surface charge on SNP. The average number SNP candidate of same size could work out using LM-20. The size and shape of SNP are determined by SEM and TEM analysis. Thus, every instrument that explores SNP has its unique specialty, which could be used for deducing specific characterization of NP.

\section{UV-Vis spectroscopic analysis}

The $100 \mu$ of SNP is taken in glass curate and diluted by $2 \mathrm{ml}$ and readings were taken in UV spectroscopic instrument. The baseline correction has been done using a distilled water and also for setting as blank reading. Figure $6 \mathrm{a}$ show UV-Vis spectroscopic analysis results at $\mathrm{pH} \mathrm{7,8,9}$ (7 days) and $\mathrm{pH} 11$ (8 days) under sun condition. The UVVis results are in accordance with the generally synthesized SNP that, as the $\mathrm{pH}$ increases the time required to form SNP decreases. UV-spectroscopic analysis scan in range of $190-800 \mathrm{~nm}$ and peak around $380-450 \mathrm{~nm}$ is specific for silver nanoparticles (Rai and yadav 2013; Sharma 2013). The basic $\mathrm{pH}$ solution assists for formation of stable SNP. The $\mathrm{pH}$ 7, 8, 9, 11 have been considered and further scale up to $\mathrm{pH} 14$ was not checked. The particle size is expected to be smaller in basic mediums. A major influence of the reaction $\mathrm{pH}$ is its ability to change the electrical charges of biomolecules that affect their capping and stabilizing abilities and subsequently the growth of the nanoparticles (Vadlapudi and Kaladhar 2014). Figure 6b showed SNP synthesis at three different conditions sun, dark, UV after $24 \mathrm{~h}$. The UV graph of dark, sun, UV synthesis of silver nano particles using leaf disc of $2 \mathrm{~cm}$ after $24 \mathrm{~h}$ confirms that the sun condition sample is best suited for silver NP and produce at $430 \mathrm{~nm}$. Absorbance of sun synthesis NP shows slight decreases after $96 \mathrm{~h}$, which comes around 0.047. The nanoparticles at sun condition are stable than room temperature, that led to study SNP at $\mathrm{pH} 11$ in details. 

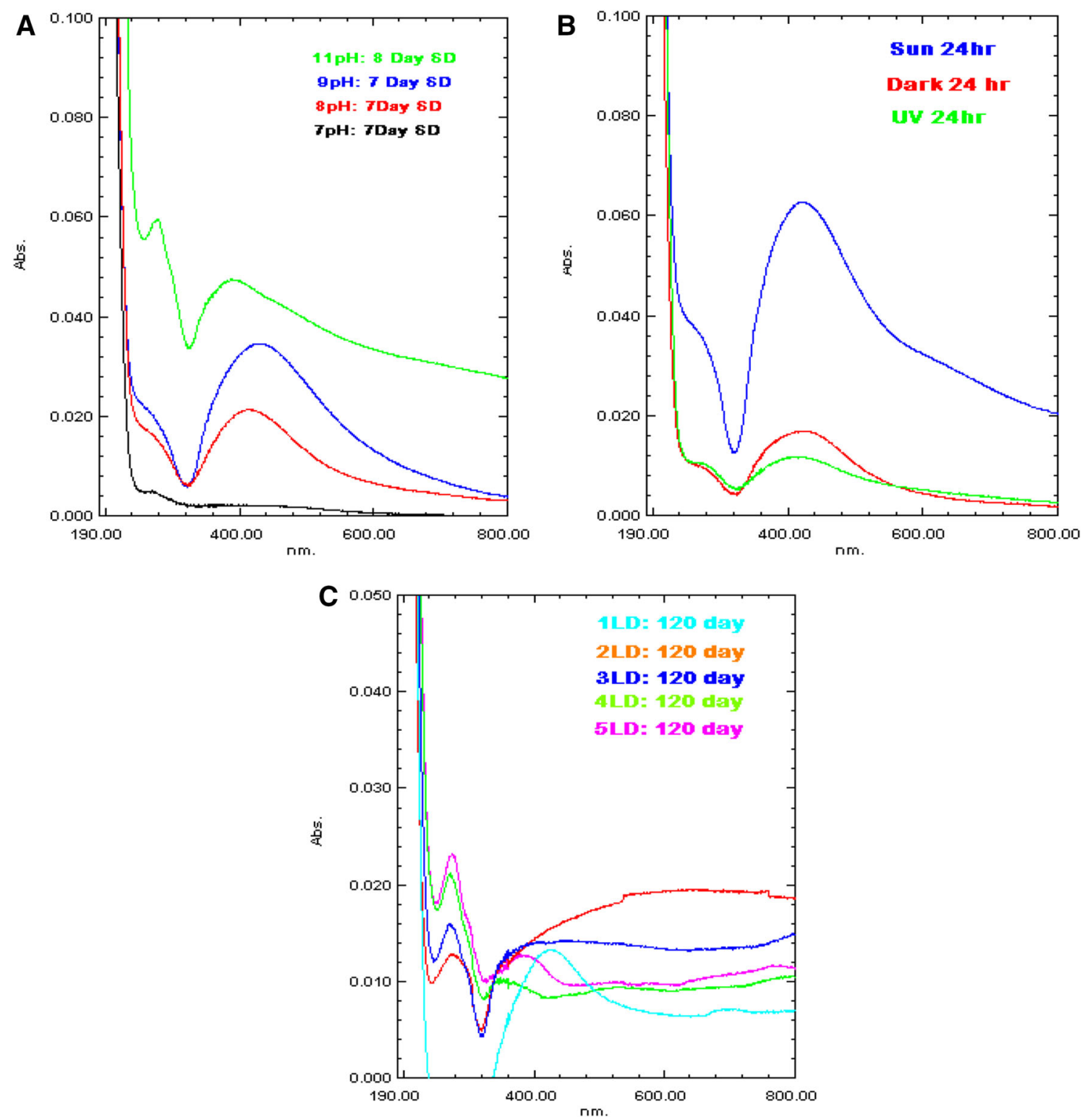

Fig. 6 It shows the silver nano particle synthesis at $\mathrm{pH} 7, \mathrm{pH} 8, \mathrm{pH} 9$, with constant $1 \mathrm{mM} \mathrm{AgNO}$ and circular single disc (SD) leaf of $2 \mathrm{~cm}$ in diameter under normal room temperature. a The UV-Vis spectroscopic analysis results are shown at $(\mathrm{pH} 7,8,9) 7$ th day and

Figure $6 \mathrm{c}$ shows an optimization of numbers of leaf discs, i.e. (one disc, 2, 3, 4, 5) for SNP synthesis at $\mathrm{pH} 11$. The single lead disc is adequate for NP synthesis. From Fig. 6c, it is concluded that the singular one leaf is effective for synthesizing SNP, the amount should still remain the same with increasing number of leaves. Nevertheless, the leaf disc number increases, the synthesis of Ag reduces. The trend should be that, as a leaf disc increases the SNP formation also increases, however, it was not observed in a present set up conditions, which might be due to some unknown error. The optimization of condition has led the selection of $\mathrm{pH} 11$ suitable for SNP formation under SUN.
(pH 11) 8th day under sun condition. b SNP synthesis at three different conditions sun, dark, UV after $24 \mathrm{~h} \mathrm{pH} 11$. c Optimization of numbers of the leaf discs, i.e. 1, 2, 3, 4, 5 for SNP synthesis at pH11. ( $L D$ leaf disc) and their stability

The alkaline $\mathrm{pH}$ environment enhanced the reducing and stabilizing capability of the antioxidants. Since the reaction was faster at $\mathrm{pH} \mathrm{11,} \mathrm{it} \mathrm{is} \mathrm{necessary} \mathrm{to} \mathrm{follow} \mathrm{the} \mathrm{rate} \mathrm{of} \mathrm{the}$ Ag NPs at pH 11 under SUN. The (Caroling et al. 2013) performed TEM analysis and found that the size of the NP particles at $\mathrm{pH} 11$ was smaller than those at $\mathrm{pH} 5$ with regular spherical shape in several methods that includes RT, SUN and microwave.

Figure 7 shows the UV spectroscopical analysis of fabricated SNP in a grade of timescale zero $\mathrm{min}, 5,10 \mathrm{~min}$, $1,2,24,48$ and 8 days. The reduction of silver nanoparticles is carried out in SUN at pH 11, A: UV spectroscopic 

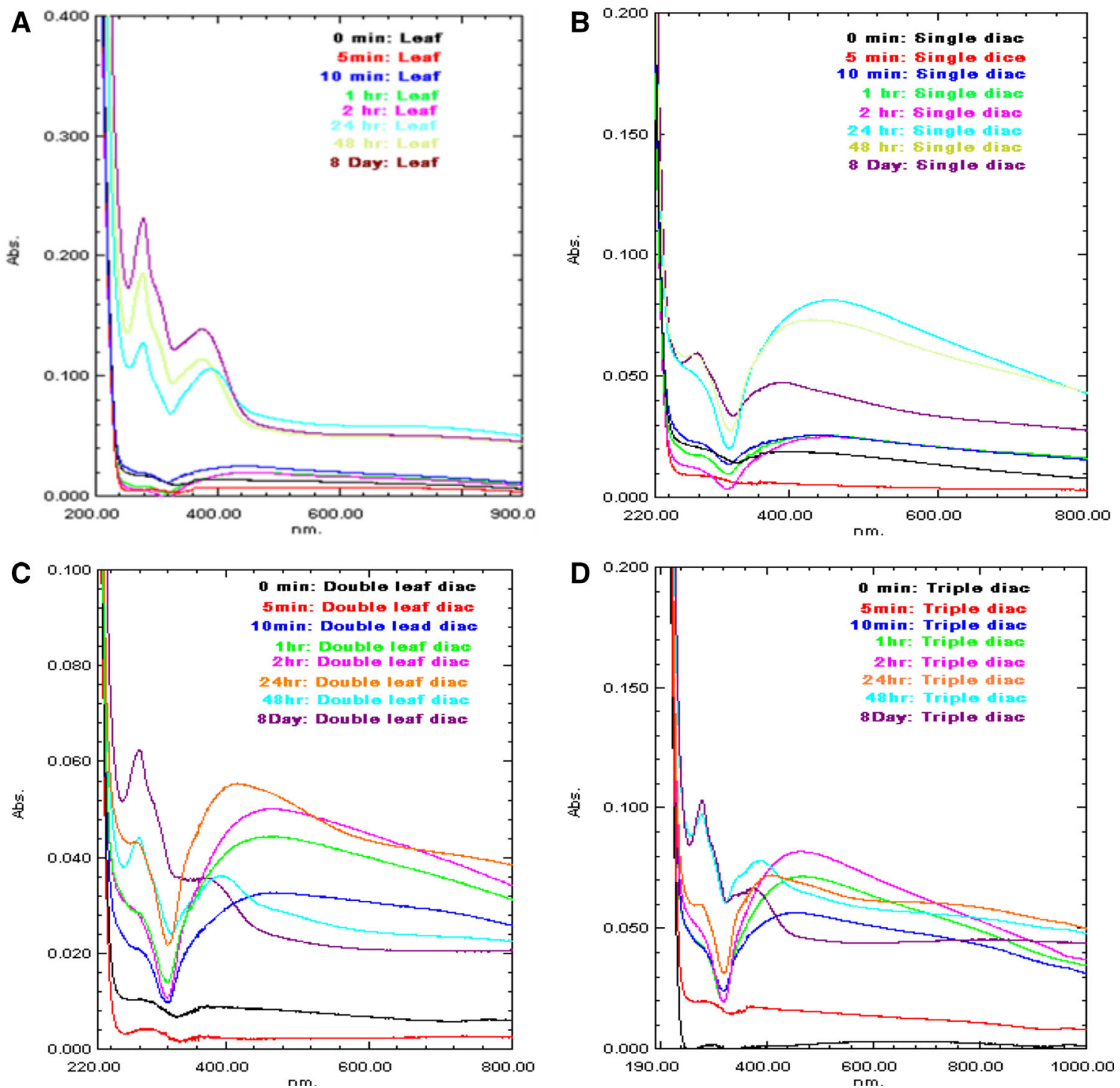

Fig. 7 Shows the UV spectroscopic analysis of fabricated SNP from P. foetida leaf disc in a grade of time scale of $0,5,10 \mathrm{~min}, 1,2,24$, $48 \mathrm{~h}, 8$ days. The reduction of silver nanoparticles is carried out in

analysis of complete leaf, B: single leaf disc, C: double lead disc, D: triple leaf disc. SUN condition: $430 \mathrm{~nm}$ : UVVis analysis confirms NP formation of sun condition. Similarly, Balavandy et al. (2014) studies the effect of stirring time on SNP prepared using glutathione as reducing agent, it produces stable SNP at $72 \mathrm{~h}$ stirring time. In contrast, (Gao et al. 2014) studied reaction time $0.5 \mathrm{~h}, 1$, $1.5,4.3 \mathrm{~h}$.

\section{FTIR analysis}

The FTIR analysis is done by centrifuging tube containing SNP for $4000 \mathrm{rpm}$ for $20 \mathrm{~min}$. The supernatant water is replaced by fresh water, and the centrifugation step repeated several times until the clean transparent

SUN at pH 11, a UV spectroscopic analysis of complete leaf, b single leaf disc, $\mathbf{c}$ double lead disc, $\mathbf{D}$ triple leaf disc

SNP is collected. Finally, the supernatant is removed and dark black SNP is allowed to be dried, and powder form is obtained. This powder of SNP is used for FTIR analysis. Figure 8 shows the FTIR analysis of A: silver nitrate, B: the FTIR analysis of $P$. foetida from young leaf veins, C: from fresh leaf part other than veins. SNP made from single lead disc. The FTIR results confirm alkanes, alkyne, amines, aliphatic amine, carboxylic acid; nitro-compound, alcohol, saturated aldehyde and phenols from the leaf disc that reduce silver nitrate to produce zero valent silver NP. (Kumar et al. 2015) also confirmed the involvement of alcoholic or polyphenolic stretching, carboxyl, conjugated carboxyl, aliphatic, aromatic, methyl, methylene and methoxy groups for SNP synthesis using FTIR in related Passiflora speices, 

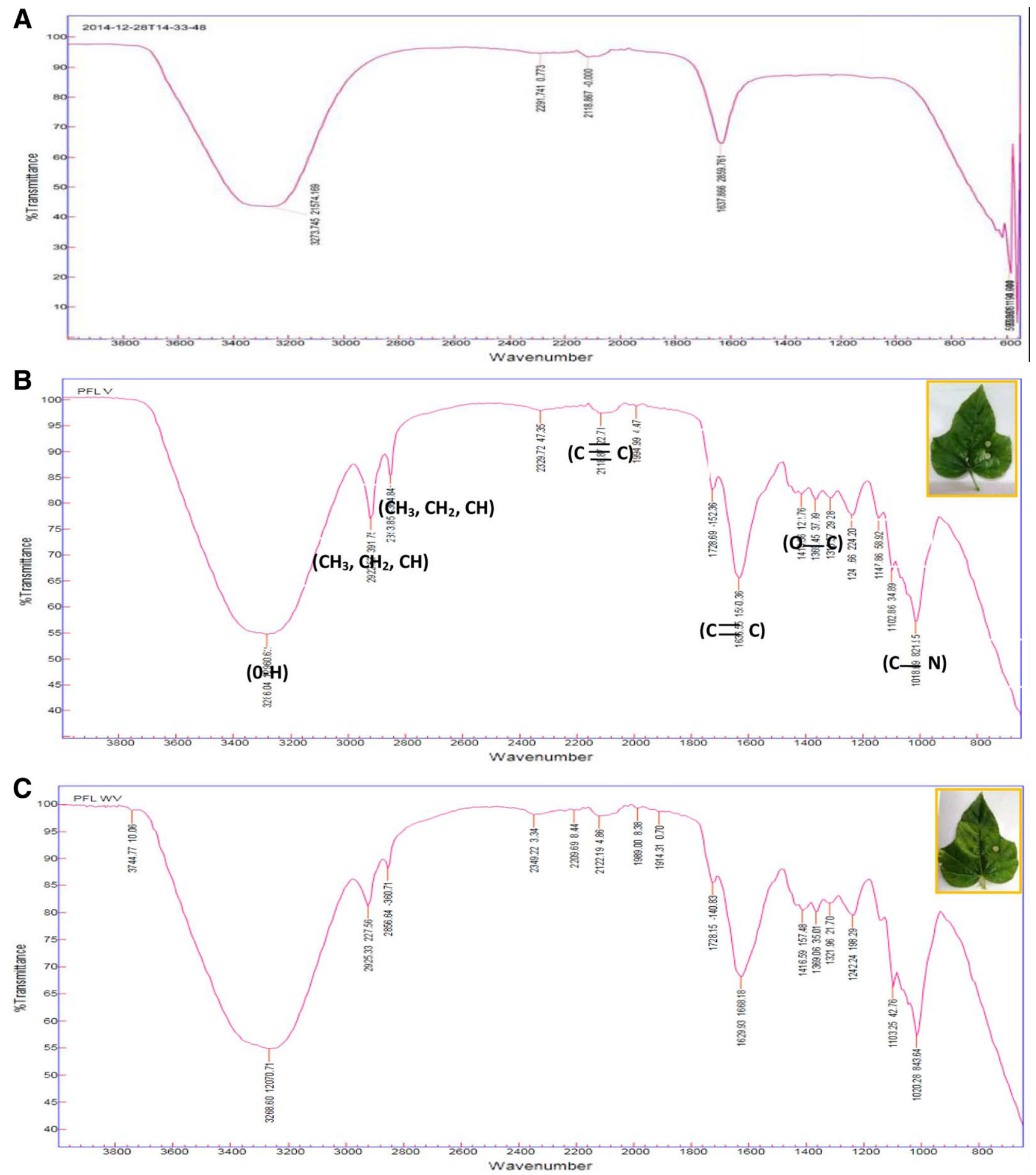

Fig. 8 It shows the FTIR analysis of a Silver nitrate, $\mathbf{b}$ the FTIR analysis of Passiflora foetida from fresh leaf veins (PF V), $\mathbf{c}$ from fresh leaf part other than veins (PF WV)

i.e. P. tripartita whose pigments are composed of glucose, $\mathrm{C}$-glycosides and $O$-glycoside derivatives that involved in reducing the $\mathrm{Ag}^{+}$to $\mathrm{Ag}^{0}$.
We were questioning ourselves for the secondary metabolites/phytochemical/functional group/elements bonding involved in silver nano reduction are from the leaf 
vein or the remaining leaf portion (see Fig. 9) shows the leaf disc in zoom mode.

\section{SEM analysis}

SEM analysis image of silver nanoparticles synthesized from leaves extracts of $P$. foetida seems to be spongy bread like in morphology (see Fig. 10). The Biologically synthesized silver nanoparticles are important in the field of nanotechnology.

The green synthesis of silver nanoparticles from Passiflora species have been studied and the ethanolic extract of $P$. foetida based SNP is reported. The few reports were in direction for synthesis and characterization of iron oxide nanoparticles prepared by $P$. foetida aqueous extract and is confirmed by UV spectroscopic analysis (Suganya et al. 2016; Shekhawat et al. 2014). The optimal conditions for interaction of phytochemicals and silver nitrate solution, reaction conditions, and selection of definite $\mathrm{pH}$ have been considered. The sizes and morphologies of the NPs may be controlled by altering some critical conditions, including substrate concentration, $\mathrm{pH}$, light, temperature, buffer strength, substrate concentration, mixing speed and exposure time.

The $1 \mathrm{mM} \mathrm{AgNO}_{3}$ as was used as standard in all experiments performed as done by (Sivaranjani and meenakshisundaram 2013). However, the reports (Gopinath et al. 2013) indicate the use of 100, $50 \mathrm{mM}$ for SNP production and fetched that as the concentration increases the particles size increases. The phytochemicals such as phenolic compounds in leaf extracts of $P$. foetida are very effective, reducing and stabilizing by forming nanoparticle based on phytochemical results. The aqueous leaf extracts of $P$. foetida appeared to be environmentally friendly, so this protocol could be used for rapid production of $\mathrm{Fe}_{2} \mathrm{O}_{3}$

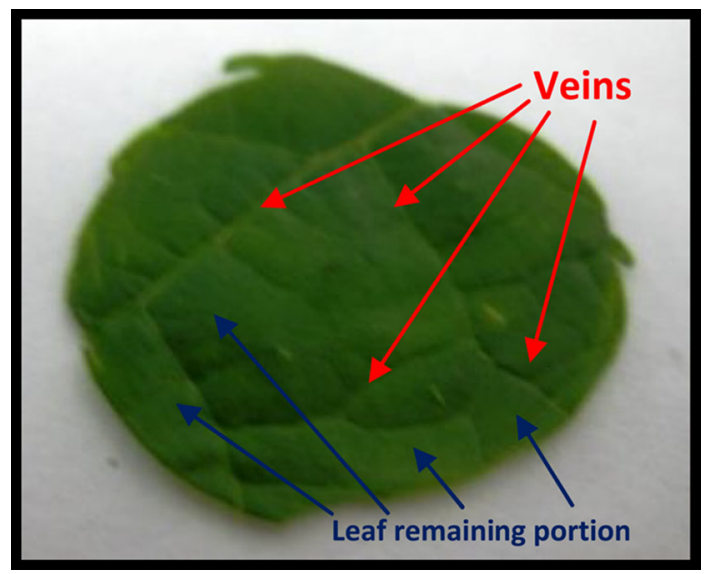

Fig. 9 The leaf disc in zoom mode showing two regions, 1st the veins indicated with black arrows (PF V) and 2nd the remaining leaf portion without veins (PF WV)

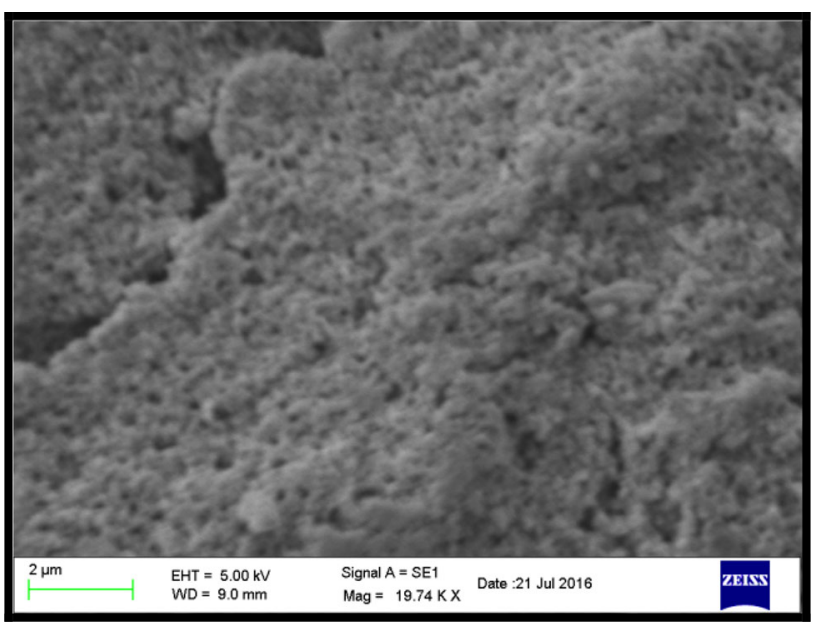

Fig. 10 Shows the SEM micrograph showing surface morphology of the silver nanoparticles of biologically synthesized silver nanoparticles using leaf disc of Passiflora foetida

nanoparticles (Kumar et al. 2015). Even though, our defined protocol is unique for SNP synthesis, which omitted the leaf extract, instead leaf discs were prepared and used for reducing silver nitrate.

In leaf disc preparation, the leaf sample may either be still attached to plant or detached from the main stem from the plant. If the leaf is attached to plant and then disc is prepared, the part attached to plant may be used as wound stress plant part for invivo studies (see Fig. 4a). Thus, the leaf disc is used for SNP synthesis, and the remaining leaf part is used for other invivo studies such as wound stress induced subordinate metabolites. This concept can be used, were stressed induced plant leaf extracts can be used probably containing a stress-induced secondary metabolites and phytochemical that may proceed with silver ions reduction and may act as capping agent and responsible for silver nanoparticles synthesis. It is reported in (Lade et al. 2014) paper a specific type of wound stress has been applied to plant leaf sample of a medicinal plant $P$. foetida and stress induced secondary metabolites has been extracted and checked for antibacterial activity. The use of such stress induced pool extracts can be considered for Ag NP formulation.

It is important to cut the leaf disc from entire leaf from middle portion as indicated in Fig. 9. Because, the disc portion after removed from full leaf must be cut from every disc circumference. This will allow the proper diffusion of secondary metabolites and phytochemicals, which are involved in reducing silver salt to zero valent silver. The leaf disc size will matter, as more the surface area the larger will be the diffusion of reducing agents. However, results shown in Fig. $6 \mathrm{c}$ are in direct contradiction, stating that single leaf disc is sufficient for SNP synthesis rather than double or more leaf disc. Thus, for standardization and optimization of some essential parameters such as $\mathrm{pH}$, leaf 
disc number and size, we have kept $2 \mathrm{~cm}$ as a standard size for disc in all experiments.

For the FTIR analysis, $\mathrm{AgNO}_{3}$, leaf sample and synthesized SNP were used. $\mathrm{AgNO}_{3}$, is common solution, and the leaf disc or the full leaf is used. However, the complete leaf or leaf disc will yield the same FTIR results. The leaf surface exhibited 100 chloroplast cells, which perform the photosynthesis function and the water and food are supplied from the leaf mid rib and veins. The leaf disc used for SNP fabrication consists of leaf surface containing veins. Thus, promote us for FTIR analysis of two portions of leaf, 1st the leaf without vein part (PF WV) and 2nd for leaf from the vein portion (PF V). Nevertheless, the FTIR analysis yields same peak in both analysis clearing the drought involvement different function group. Similar to (Kumar et al. 2015) we also confirmed that alkanes, alkyne, amines, aliphatic amine, carboxylic acid; nitro-compound, alcohol, saturated aldehyde and phenols takes part in reducing silver nitrate to produce zero valent silver NP. The SEM result shows a bread like morphology, and synthesized SNP appears to form a cluster because of denaturation and aggregation during the sputtering process. Similar to the observation of (Kumar et al. 2015) which conclude SEM analysis of synthesized Iron Oxide nanoparticles as agglomerated due to adhesive nature of distorted irregular cluster appearance prepared from leaf extract of $P$. foetida. The SEM was used to determine its morphology and FTIR analysis done to evaluate function group from $P$. foetida involved in reduction of iron oxide (Suganya et al. 2016; Kumar et al. 2015; Shekhawat et al. 2014).

The silver nanoparticles from singular leaf disc of $P$. foetida $\mathrm{pH} 9$ are stable until 7th days/single leaf disc $\mathrm{pH} 11$ stable until 120 days. The sun condition SNP at pH 11 could be raised for evaluation of antimicrobial activity. The sun light could play an intense role in reducing silver ion to SNP. The SUN light intensity, duration of sun light could be factors responsible for definite size and shape of SNP. The SNP at RT took more time than sun, which forms SNP in no time upon its exposure to sun. The sun assisted SNP are found to produce quick and are of smaller size as compared to UV and dark. This may be due to the light induced enzyme that may be present in extract, which get activated upon receiving sun light. The detailed characterization using TEM will revel its size. The morphology of iron oxide NP was identified as spherical and average size of $20 \mathrm{~nm}$ diameter. Green synthesis of $\mathrm{Fe}_{2} \mathrm{O}_{3}$ nanoparticles using $P$. foetida be relatively safe and particles possesses significant biological activity (Suganya et al. 2016). Finally, some of the advantages of the leaf discs for silver nanoparticles are given here. It minimizes the time required for leaf extract preparation, it is simple, easy, low cost, non toxic, no labor skills and monitoring required.

\section{Conclusion}

The leaf disc of $P$. foetida is found suitable for silver nanoparticles synthesis. It was concluded that single leaf disc $(2 \mathrm{~cm})$ is only proficient at produced stable nanoparticles. It is UV-Vis spectroscopically confirmed that current method of silver nano fabrication is skilful in reducing silver ions into silver atoms using circular leaf disc of $2 \mathrm{~cm}$ alone. The leaf disc at $\mathrm{pH} 7$ was inefficient to produced $\mathrm{Ag}$ NP. The alkaline $\mathrm{pH}$ from 11 was used successfully for fabrication of SNP. Ag-NP complex synthesis was started within $24 \mathrm{~h}$ at room temperature and $10 \mathrm{~min}$ in sun. Reaction carried under sun condition is showing sharp peak at UV-Vis absorbance and found suitable and favors the silver nano particle synthesis when compared with dark and UV conditions. The FTIR results confirmed that alkanes, alkyne, amines, aliphatic amine, carboxylic acid; nitro-compound, alcohol, saturated aldehyde and phenols functional group has been participated in reduction of silver. SEM analysis clearly figured its bread like morphology and nanoparticles appears in cluster. Further to specify its size TEM needs to be performed to establish a current method for use with other plant species for nanofabrication.

Acknowledgements My first thanks to Department of Biotechnology and Head \& Professor, Dr. M. K. Rai for providing research facility and to permit me to carry out research work at Department of Biotechnology, Sant Gadge Baba Amravati University, Amravati 444602 Maharashtra, India. I would like to acknowledge University Grant Commission, New Delhi India for BSR fellowship. I would like to thanks and mention Dr A. S. Patil (Professor) for being my guide suggesting throughout work and for valuable discussion. I am obliged to my all-time mentor Dr S. B. Nandeshwar (Principle Scientist), Dr. V. N. Waghmare (Principle Scientist) Central Institute for Cotton Research, Nagpur, India and Dr. Andreas Kukol (Professor) School of Life Science, University of Hertfordshire, Hatfield, United Kingdom.

Authors' contributions BDL idea, designed, experimentation and wrote the manuscript. ASP suggestion, Both authors read and approved the final manuscript.

\section{Compliance with ethical standards}

Conflict of interest The authors declare that they have no competing interests. BDL generated the idea for development of silver nanoparticles using leaf disc that uses less time for fabrication in greener way.

Open Access This article is distributed under the terms of the Creative Commons Attribution 4.0 International License (http:// creativecommons.org/licenses/by/4.0/), which permits unrestricted use, distribution, and reproduction in any medium, provided you give appropriate credit to the original author(s) and the source, provide a link to the Creative Commons license, and indicate if changes were made. 


\section{References}

Arokiyaraj S, Arasu MV, Vincent S et al (2014) Rapid green synthesis of silver nanoparticles from chrysanthemumindicum lands its antibacterial and cytotoxic effects: an in vitro study. Int $\mathrm{J}$ Nanomed 9(1):379-388

Balavandy SK, Shameli K, Awang Biak DRB, Abidin ZZ (2014) Stirring time effect of silver nanoparticles prepared in glutathione mediated by green method. Chem Cent J 8:11

Banerjee P, Satapathy M, Mukhopahayay A, Das P (2014) Leaf extract mediated green synthesis of silver nanoparticles from widely available Indian plants: synthesis, characterization, antimicrobial property and toxicity analysis. Bioresour Bioprocess 1(3):2-10

Bhosale RR, Kulkarni AS, Gilda SS, Aloorkar NH, Osmani RA (2014) BR Harkare. Int J Pharm Sci Nanotechnol 7(1):2328-2337

Bonde S (2011) A biogenic approach for green synthesis of silver nanoparticles using extract of Foeniculum vulgare and its activity against Staphylococcus aureus and Escherichia coli. Nusant Biosci 3(2):59-63

Brindha D, Vinodhini S, Alarmelumangai K (2012) Fiber dimension and chemical contents of fiber from Passiflora foetida, 1 . and their suitability in paper production. Sci Res Rep 2(3):210-219

CABI (2017) http://www.cabi.org/isc/datasheet/38800. Accessed 22 Feb 2017

Caroling G, Tiwari SK, Ranjitham M, Suja R (2013) Biosynthesis of silver nanoparticles using aqueous broccoli extract-characterization and study of antimicrobial, cytotoxic effects. Asian J Pharm Clin Res 6(4):165-172

Dhawan K, Dhawan S, Sharma A (2004) Passiflora a review update. J Ethnopharmacol 94:1-23

Echeverri F, Arango V, Quinones W, Torres F, Escobar G, Rosero Y, Archbold R (2001) Passifloricins, polyketides alpha-pyrones from Passiflora foetida resin. Phytochemistry 56(8):881-885

Gao Y, Huang Q, Su Q, Liu R (2014) Green synthesis of silver nanoparticles at room temperature using Kiwifruit juice. Spectrosc Lett 47:790-795

Garboza LH, Corona FO (1994) Diagnosis of Xylella fastidiosa in grape and weeds associated with this crop. Manejo Integrado de Plagas 33:7-10

Ghosh D, Saadi I, Mondal AK, Mondal S (2015) Biosynthesis of silver nano-particle from four medicinally important taxa in South West Bengal, India. Nano Vision 5(11):305-312

Gopinath K, Gowri S, Arumugam A (2013) Phytosynthesis of silver nanoparticles using Pterocarpus santalinus leaf extract and their antibacterial properties. J Nanostruct Chem 3:68

Husen A, Siddiqi S (2014) Photosynthesis of nanoparticles: concept, controversy and application. Nanoscale Res Lett 9:229

Iravani S (2011) Green synthesis of metal nanoparticles using plants. Green Chem 13:2638-2650

Iravani S, Korbekandi H, Zolfaghari B (2014) Synthesis of silver nanoparticles: chemical, physical and biological methods. Res Pharm Sci 9(6):385-408

Keat CL, Aziz A, Eid AM, Elmarzugi NA (2015) Biosynthesis of nanoparticles and silver nanoparticles. Bioresour Bioprocess 2:47

Kesharwani J, Yoon KY, Hwang J, Rai M (2009) Phytofabrication of silver nanoparticles by leaf extract of Daturametel, hypothetical mechanism involved in synthesis. J Bionanosci 3:39-44

Kharissova OV, Kharisov BI, Garcia TM, Mendez UO (2009) A Review on less-common nanostructures. Synth React Inorg MetOrg Nano-Met Chem 39:662-684

Kharissova OV, Dias HVR, Kharisov BI, Perez BO, Perez VMJ (2013) The greener synthesis of nanoparticles. Trends Biotechnol 31:240-248

Kumar B, Smita K, Cumbal L, Debut A, Camacho J, HernandezGallegos E, Chavez-Lopez MDG, Grijalva M, Angulo Y, Rosero
G (2015) Pomosynthesis and biological activity of silver nanoparticles using Passiflora tripartita fruit extracts. Adv Mater lett 6(2):127-132

Lade BD (2015) Medicinal values of Passiflora foetida. New Approaches for fast agriculture production. In: Agrobios news letter, chap 43, vol. 13, no. 10, Art no. 11342, pp 68-70. ISSN-972-7027

Lade BD, Patil AS, Paikrao HM (2014) Systematic optimization of thin-layer chromatography for wound-induced differential secondary metabolites in Passiflora foetida. J Planar Chromatogr 27(5):385-391

Lijavetzky D, Almagro L, Belchi-Navarro S, Martínez-Zapater JM, Bru R, Pedreno MA (2008) Synergistic effect of methyljasmonate and cyclodextrin on stilbene biosynthesis pathway gene expression and resveratrol production in Monastrell grapevine cell cultures. BMC Res Notes 1:132

Mohanasundari C, Natarajan D, Srinivasan K, Umamaheswari S, Ramachandran A (2007) Antibacterial properties of Passiflora foetida L. A common exotic medicinal plant. Afr J Biotech 6(23):2650-2653

Nano Composix (2012) Zeta Potential Analysis Of Nanoparticles, version 1.1. Nanocomposix, San Diego, CA, pp 1-6

Patil AS, Paikrao HM (2012) Bioassay guided phytometabolites extraction for screening of potent antimicrobials in Passiflora foetida L. J Appl Pharm Sci 2(9):137-142

Patil AS, Paikrao HM, Patil SR (2013) Passiflora foetida Linn: a complete morphological and phytopharmacological review. Int J Pharma Bio Sci 4(1):285-296

Prabhu S, Poulose EK (2012) Silver nanoparticles: mechanism of antimicrobial action, synthesis, medical applications, and toxicity effects. Int Nano Lett 2:32

Pushpa Rani V, Amila Meera K (2015) Phytochemical analysis and in vitro cytogenetics assay of chromosomal aberration on peripheral human blood lymphocytes by the leaf crude extractPassiflora foetida L. Biolife 3(1):154-163

Rai M, Yadav A (2013) Plants as potential synthesizer of precious metal nanoparticles: progress and prospects. IET Nanobiotechnol 7(3):117-124

Rai MK, Deshmukh SD, Ingle AP, Gade AK (2012) Silver nanoparticles: the powerful nanoweapon against multidrugresistant bacteria. J Appl Microbiol 112(5):841-852

Sadowski Z (2010) Biosynthesis and applications of silver and gold nanoparticles. In: Pozo Perez D (ed) Silver Nanoparticles. InTech, Rijeka, pp 257-276. ISBN 978-953-307-028-5

Sharma YR (2013) Elementary organic spectroscopy; principles and chemical applications, Chapter 3. S Chand and Company Pvt. Ltd, New Delhi, pp 75-161

Shekhawat MS, Ravindran CP, Manokari M (2014) Biosynthesis of zinc oxide nanoparticles from Passiflora foetida $\mathrm{L}$. Extracts and their characterization. Int J Green Herb Chem A Green Chem 3(2):518-523

Singh K, Panghal M, Kadyan S, Chaudhary U, Yadav JP (2014) Green silver nanoparticles of Phyllanthus amarus: as an antibacterial agent against multi drug resistant clinical isolates of Pseudomonas aeruginosa. J Nanobiotechnol 12:40

Sivaranjani K, Meenakshisundaram M (2013) Biological synthesis of silver nanoparticles using Ocimum bassilicum extract and their antimicrobial activity. Int Res J Pharm 4(1):225-229

Suganya D, Rajan MR, Ramesh R (2016) Green synthesis of iron oxide nanoparticles from leaf extract of Passiflora foetida and its antibacterial activity. Int J Curr Res 8(11):42081-42085

Vadlapudi V, Kaladhar DSVGK (2014) Review: green synthesis of silver and gold nanoparticles. Middle-east J Sci Res 19(6):834-842

Vijayaraghavan K, Nalini S, Prakash NU, Madhankumar D (2012) One step green synthesis of silvernano/microparticles using extracts of Trachyspermum ammi and Papaver somniferum. Colloid Surf B Biointerfaces 94:114-117 